\title{
Cardiac hypertrophy associated with myeloproliferative neoplasms in JAK2V617F transgenic mice
}

\author{
Kaiyao Shi ${ }^{1,2}$, Wanke Zhao ${ }^{2}$, Yun Chen ${ }^{2}$, Wanting Tina $\mathrm{Ho}^{2}$, Ping Yang ${ }^{{ }^{*}}$ and Zhizhuang Joe Zhao ${ }^{2^{*}}$
}

\begin{abstract}
Background: Myeloproliferative neoplasms (MPNs) are blood malignancies manifested in increased production of red blood cells, white blood cells, and/or platelets. A major molecular lesion associated with the diseases is JAK2V617F, an activation mutation form of tyrosine kinase JAK2. Cardiovascular events represent the leading cause of morbidity and mortality associated MPNs, but the underlying mechanism is not well understood.

Methods: Previously, we generated JAK2V617F transgenic mice which displayed MPN-like phenotypes. In the present study, we further characterized these mice by analyzing the time course of MPN phenotype development and associated cardiac abnormalities. We performed detailed histochemical staining of cardiac sections.

Results: JAK2V617F transgenic mice developed cardiomegaly as a subsequent event of increased blood cell production during the course of MPN phenotype development. The cardiomegaly is manifested in increased ventricular wall thickness and enlarged cardiomyocytes. Trichrome and reticulin staining revealed extensive collagen fibrosis in the heart of JAK2V617F transgenic mice. Thrombosis in the coronary artery and inflammatory cell infiltration into cardiac muscle were also observed in JAK2V617F transgenic mice, and the latter event was accompanied by fibrosis.

Conclusion: JAK2V617F-induced blood disorders have a major impact on heart function and lead to cardiac hypertrophy. JAK2V617F transgenic mice represent an excellent model system to study both hematological malignancies and cardiovascular diseases.
\end{abstract}

Keywords: MPN, JAK2V617F, Hematological malignancies, Fibrosis, Cardiomegaly, Cardiac hypertrophy

\section{Background}

Myeloproliferative neoplasms (MPNs) are chronic hematopoietic malignancies characterized by abnormal amplification of one or more myeloid lineages [1-3]. These diseases include polycythemia vera (PV), essential thrombocythemia (ET), and primary myelofibrosis (PMF) [4,5]. PV patients have increased production of all three types of blood cells, whereas ET patients mainly show elevations of platelets. Patients with PMF develop fibrous (scar-like) tissues in the bone marrow as a result of abnormal myeloid proliferation. MPNs mainly affect older people with an average onset of 55 years. So far, there is no effective

\footnotetext{
* Correspondence: pyang@jlu.edu.cn; Joe-zhao@ouhsc.edu

'Department of Cardiology, China-Japan Union Hospital of Jilin University, Changchun 130021, China

2Department of Pathology, University of Oklahoma Health Sciences Center, Oklahoma City, Oklahoma 73104, USA
}

cure for the diseases [6-9]. Complications associated with MPNs include thrombosis, hemorrhage, heart attacks, strokes, myeloid metaplasia, and acute leukemia. Strokes and heart attacks caused by these diseases are usually fatal. In fact, cardiovascular events represent the leading cause of morbidity and mortality in the course of PV and ET [10-12]. However, how the blood abnormality associated with MPNs leads to cardiac changes is not well understood.

JAK2V617F, a mutant form of tyrosine kinase JAK2, represents a major molecular defect in MPNs [13-17]. It is found in over $95 \%$ of PV and over 50\% of ET and PMF cases [1-3,18]. In early studies, we have generated JAK2V617F transgenic mice by using the vav-1 promoter which drives transgene expressions in the hematopoietic system. JAK2V617F transgenic mice display MPN-like 
phenotypes with increased levels of red blood cells, platelets, and white blood cells [19]. These mice thus represent a model system to study MPNs and associated complications. In the present study, we investigated cardiac changes and remodeling during the course of MPN phenotype development in these mice. Our data demonstrate that JAK2V617F transgenic mice display cardiac hypertrophy manifest in increased ventricular wall thickness, enlarged cardiomyocytes, and formation of collagen fibrosis in the heart. Our study thus links a chronic blood malignancy directly to heart diseases.

\section{Results}

\section{JAK2V617F transgenic mice displayed cardiomegaly}

Previously, we have generated JAK2V617F transgenic mice that displayed MPN-like phenotypes with elevated platelet and red blood cell counts [19]. This provides us with a model system to study MPNs and complications associated with MPNs. We employed homozygous line A JAK2V617F transgenic mice in this study to demonstrate the effects of JAK2V617F-induced MPN phenotypes on heart function. Initially, we noticed apparent cardiomegaly, namely, heart enlargement, in these mice as illustrated in Figure 1A. Further detailed analyses of more than 10 mice in each group revealed that cardiomegaly was seen in JAK2V617F transgenic mice at 9 weeks of age $(\mathrm{P}<0.05)$ and became more remarkable as the mice aged (Figure 1B). At the age of 40-45 weeks, hearts from JAK2V617F transgenic mice were nearly $30 \%$ heavier than those of control mice on average $(\mathrm{P}<0.001)$. When the body weight is taken into consideration, the difference is more prominent because at 40-45 weeks, the transgenic mice weighed significantly less than the control mice (Figure $1 \mathrm{C}$ and D). Note that at a younger age of 5 weeks, there is no difference in the heart mass although the transgenic mice clearly showed MPN phenotypes as indicated by elevated levels of red blood cells and platelets (Figure $1 \mathrm{E}$ and F). The data suggest that the onset of MPN phenotypes preceded the development of cardiomegaly in JAK2V617F transgenic mice. The cardiomegaly is apparently not from birth but rather developed as a consequence of MPNs.

We employed mice of 40-45 weeks to characterize the cardiomegaly further. Microscopic examinations of hematoxylin and eosin (H\&E)-stained cardiac sections under low magnification revealed significant thickening of the left ventricular wall in the JAK2V617F transgenic mice $(\mathrm{P}<0.01$, Figure 2). Further exanimation under high magnification demonstrated enlarged cardiomyocytes $(\mathrm{P}<0.001$, Figure 3$)$. On average, the cells from the transgenic mice were $30 \%$ bigger in area than the control. In addition, enlarged nuclei were seen in some hypertrophic cardiomyocytes (Figure 3D), suggesting an increase in DNA ploidy due to DNA replication in the absence of cell division. Therefore, the cardiomegaly observed in JAK2V617F transgenic mice can be partly attributed to thickening of the left ventricular wall and enlargement of cardiomyocytes.

\section{JAK2V617F transgenic mice developed fibrosis in the heart}

To define the cellular and molecular mechanism underlying the development of cardiomegaly in JAK2V617F
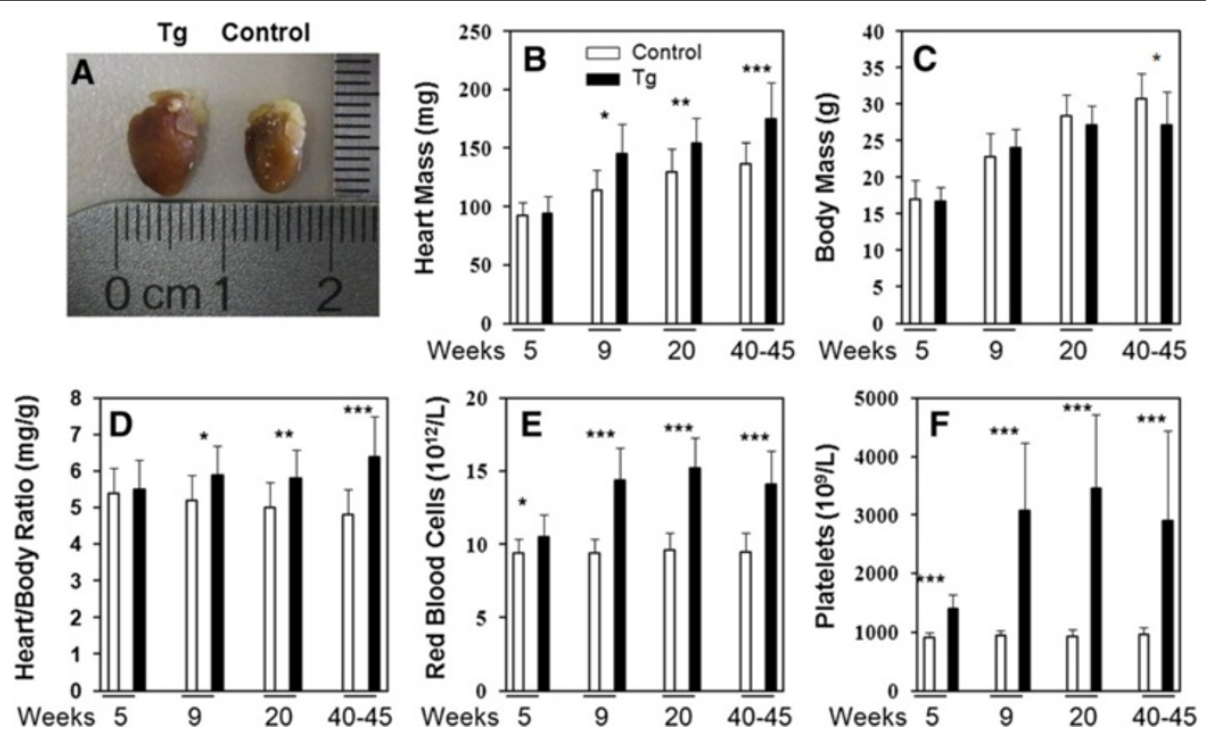

Figure 1 JAK2V617F mice develop cardiomegaly associated with increased blood cell counts. Photos of hearts from typical control and JAK2V617F transgenic mice at age of 40-45 weeks are shown (A). Bar graphs represent average heart mass (B), body mass (C), heart/body ratio (D), red blood cell counts (E), and platelet counts (F) of control (open bar) and JAK2V617F transgenic (closed bar) mice at indicated ages. Error bars denote standard deviation $(n \geq 10)$. ${ }^{*} P<0.05$, ${ }^{* *} P<0.01$, ${ }^{* *} P<0.001$. 


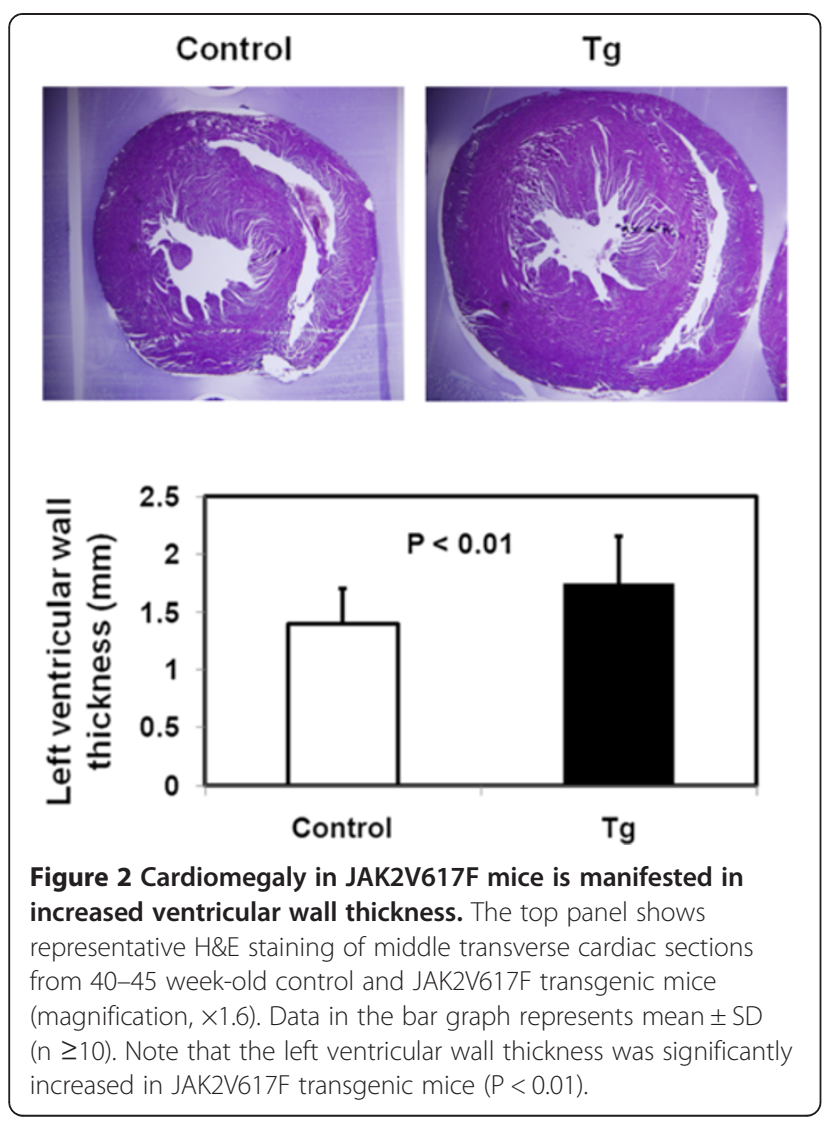

transgenic mice, we performed Masson's trichrome staining, a commonly used method to detect collagen fibers. As indicated by the bright blue staining, prominent collagen fibrosis was observed in the left ventricle of transgenic mouse hearts (Figure 4). The fibrosis occurred in both interstitial and perivascular regions (Figure $4 \mathrm{~B}$ and D, respectively). In contrast, trichrome staining in the correspondent regions of control mouse hearts was marginal (Figure 4A and C).

Since the Masson's trichrome staining mainly detects type I collagen, we further employed reticulin staining to investigate type III collagen. As shown in Figure 5, very intensive and thick interstitial reticulin fibers were observed with the transgenic mice. Reticulin staining in the cell-cell junction of control mouse hearts was also apparent but were much thinner. The data thus demonstrated a much higher amount of type III collagen in the heart of JAK2V617F transgenic mice.

The most abundant extracellular matrix proteins in the heart are collagens, particularly the collagen type I and type III phenotypes $[20,21]$. Our study thus revealed substantial accumulation of collagen fibrosis in the heart of JAK2V617F transgenic mice. This contributes to major cardiac remodeling and may significantly affect the heart function.

\section{Coronary artery thrombosis and inflammatory cell infiltration were found in the heart of JAK2V617F transgenic mice}

We further examined at least 5 selected H\&E-stained cardiac sections from each of 20 control and 20 JAK2V617F transgenic mice of 40-70 weeks of age. We found occurrence of thrombosis in the coronary artery of 4 transgenic but not a single control mice (Figure 6). This suggests that some of the transgenic mice may have suffered from heart attack. Coronary artery thrombosis typically causes acute myocardial infarction. This can further deteriorate cardiac hypertrophy. We also noticed that cardiac sections from 5 JAK2V617F transgenic mice but not at all from control mice had infiltration of inflammatory cells as demonstrated in Figure 7. Trichrome and reticulin staining revealed collagen fibrosis in the affected regions. Interestingly, toluidine blue staining showed that mast cells were among the infiltrated inflammatory cells. Mast cells has increasingly been recognized as effector cells in many cardiovascular diseases, and many mast-cell-derived proteases have detrimental effects on blood vessel structure while mast cell-derived cytokines and chemokines can promote vascular inflammation $[22,23]$.

\section{Real time PCR analyses revealed a minimal expression of transgenic JAK2V167F in the mouse heart}

The cardiac hypertrophy observed in JAK2V617F mice is likely a consequence of MPN phenotype. However, there is a possibility that the JAK2V617F expression may directly affect cardiomyocytes. In fact, an earlier study revealed the presence of JAK2V617F in cardiomyocytes from a patient with MPNs and hypertrophic cardiomyopathy [24]. To determine the expression of endogenous Jak2 and transgenic JAK2V617F in the heart, we performed real time PCR analysis with specific primers as described previously [19]. Expression of these genes in hematopoietic tissues including bone marrow, peripheral blood, and spleen were included for comparison. Despite containing 26 copies of the JAK2V617F transgenic gene [19], mRNA transcripts of JAK2V617F were nearly 10 -fold below the expression level of endogenous mouse Jak2 in the hematopoietic tissues. Mouse Jak2 was expressed at a substantial level in the heart, which is consistent with the crucial role of JAK2 in cardiomyogenesis [25]. However, expression of transgenic JAK2V617F in the heart was much lower, about 200-fold below the level of mouse Jak2 in the heart or of JAKV617F in the hematopoietic tissues. This low-level JAK2V617F expression may be mainly attributable to the presence of residual blood cells in the cardiac blood vessels. The data thus demonstrate a minimal expression of JAK2V617F transgene in mouse heart cells. Although we cannot totally rule out the contribution of JAK2V617F expression in cardiomyocytes to the development of cardiac hypertrophy phenotypes, the possibility for this is very low. 


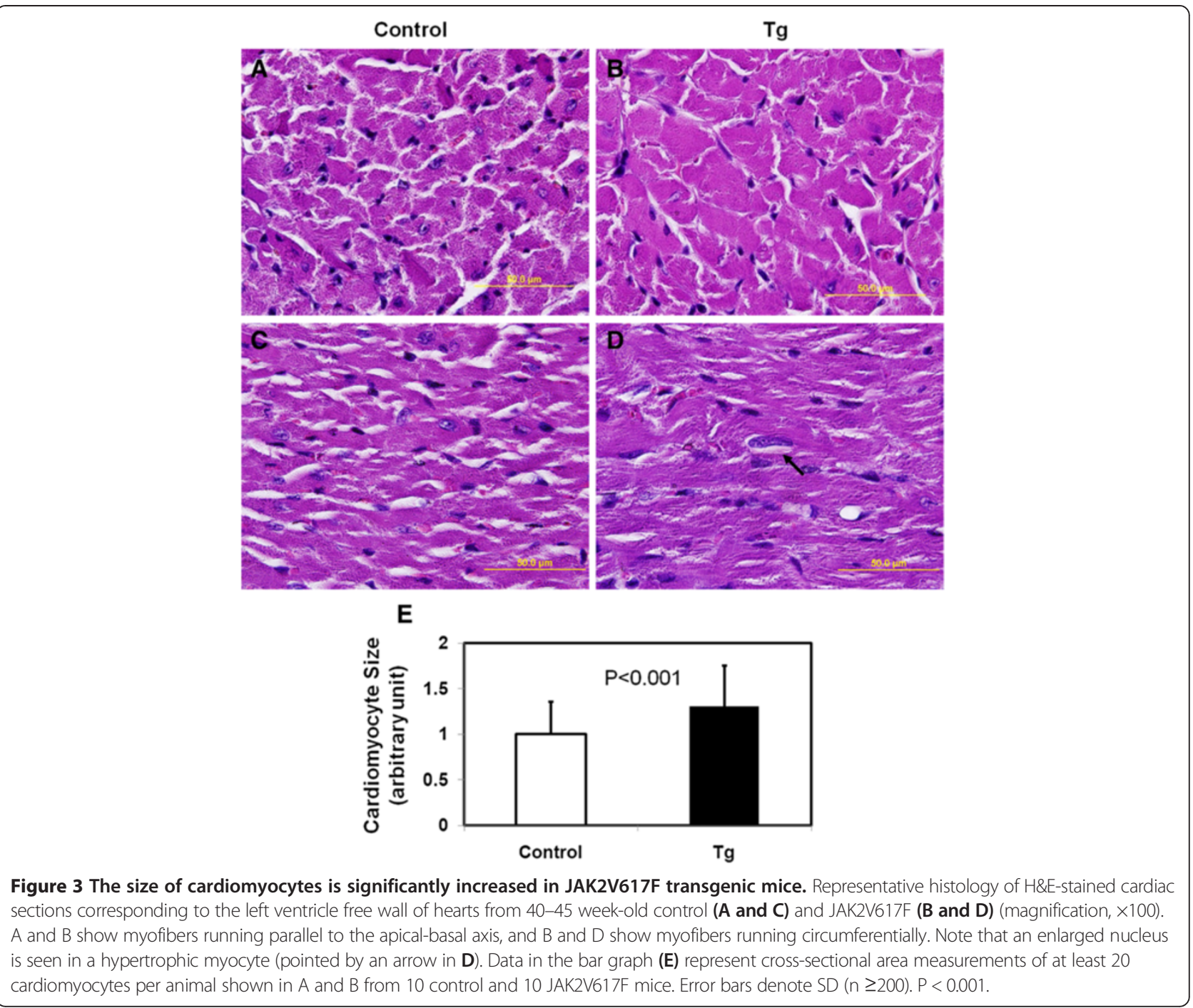

\section{Discussion}

By using JAK2V617F transgenic mice, this study demonstrates a direct association of JAK2V617F-induced MPN phenotypes with heart diseases. We believe that the later complication is a consequence of the former condition. This is supported by the fact that the development of MPN phenotype preceded the onset of cardiomegaly in these transgenic mice. In addition, the JAK2V617F transgene is controlled by the $v a v-1$ gene promoter which drives gene expression specifically in hematopoietic cells with minimal expression in the heart (see Figure 8 and ref. $[19,26])$. Therefore, JAK2V617F primarily affects the blood cells which in turn exert effects on cardiomyocytes and other cells in the heart through various physical and chemical interactions. Our study established a causal link between the MPN blood malignancy and heart diseases. This provides a mechanistic explanation for the high morbidity and mortality of MPN patients due to cardiovascular events [10-12]. JAK2V617F transgenic mice thus represent an excellent system to study cardiovascular diseases as well as blood disorders.

Cardiomegaly can usually be caused by coronary artery diseases or high blood pressure (hypertension). On one hand, we observed the occurrence of thrombosis in the canary artery of JAK2V617F transgenic mouse heart. This can presumably cause myocardial ischemia thereby leading to cardiac enlargement, and the increased platelets in the transgenic mice may contribute a higher incidence of thrombotic events. On the other hand, hypertension may represent a more general phenotype in the transgenic mice. High red blood cells in these mice directly increase blood viscosity and thus raise the peripheral resistance. It has been well documented that high red blood cells and hematocrit lead to hypertension [27-30]. In fact, hypertension 


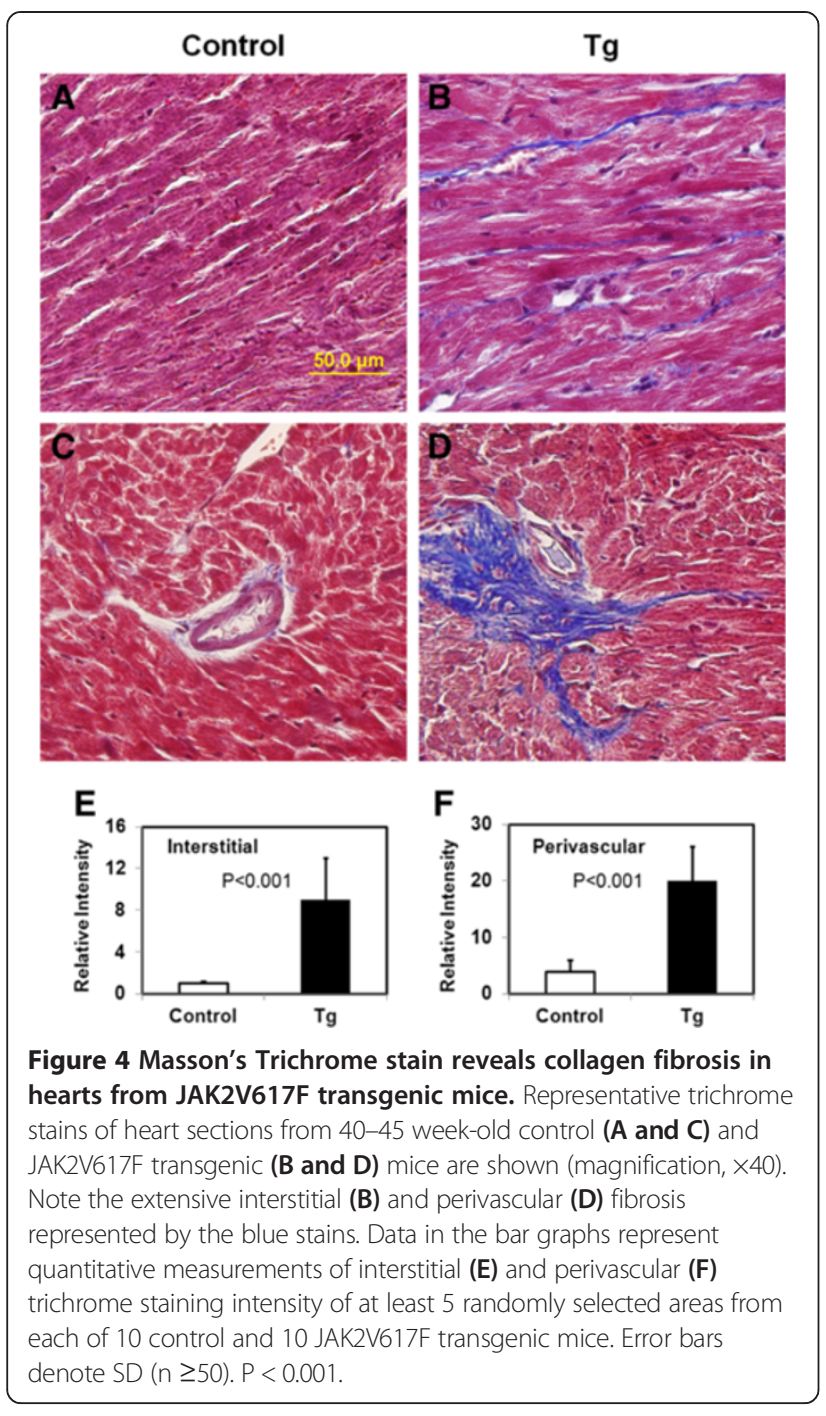

and thrombosis are common initial presentation and complications with MPN patients. Our data suggest these patients may also develop cardiomegaly.

Our study revealed substantial accumulation of collagen fibers in the heart of JAK2V617F transgenic mice. This can contribute significantly to cardiac hypertrophy in addition to increased cardiomyocyte size. Cardiac fibrosis is considered to be the key to understanding heart disease. Recent research points to several key signaling pathways involved in cardiac fibrosis, providing biomarkers and potential targets for intervention. The JAK2V617F transgenic mice serve as a good in vivo system to dissect these pathways and identify growth factors and cytokines that trigger the activation of these pathways. Among the extracellular matrix in the heart, collagens are the most abundant fibrillar proteins [20,21]. Previous studies have mainly focused on type I collagen. Type I collagen can be detected by trichrome staining as shown in Figure 4, and it forms thick fibrils. However, type III collagen is also abundant in the

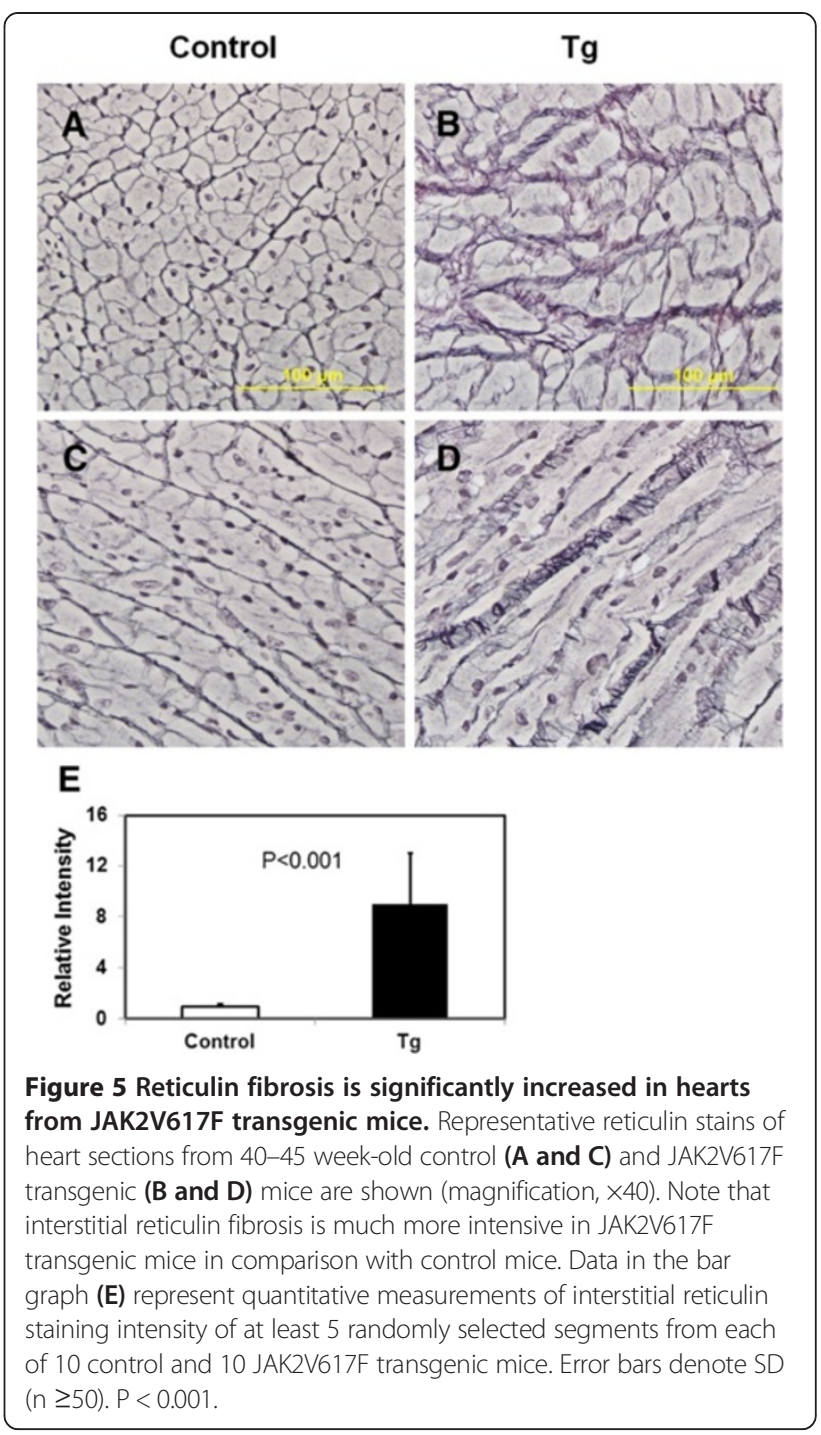

heart but is seldom examined. Type III collagen forms socalled reticulin thin fibers. By using silver staining, we found a more profound change in the level of reticulin fibers in the extramyocyte space of hearts from JAK2V617F transgenic mice. Therefore, this method should be generally used to detect fibrosis in the heart. Reticulin fibers are also found in the liver, kidney and the spleen. Interestingly, JAK2V617F transgenic mice developed myelofibrosis in the bone marrow and spleen [1-3]. This is also recapitulated in JAK2V617F mice [19]. The myelofibrosis is mainly caused by accumulation of reticulin fibers. We believe that the reticulin fibers found in the heart of JAK2V617F transgenic mice may be caused by a similar mechanism by which myelofibrosis is regulated.

Inflammation has a major role in cardiac hypertrophy. Importantly, we observed infiltration of inflammatory cells in the muscle of hearts from JAK2V617F transgenic mice. This inflammatory reaction may be triggered by a 


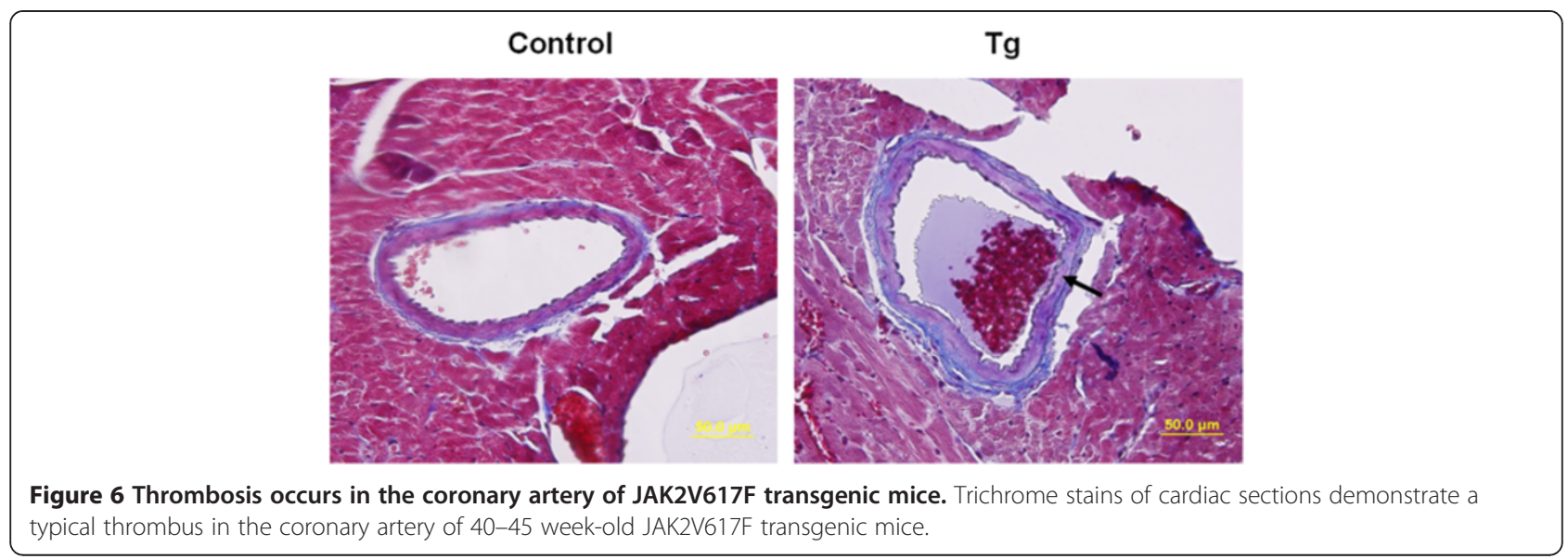

cell necrosis due to myocardial infarction. Necrotic cells release soluble factors that cause migration of inflammatory cells and fibroblasts to the site of injury for repairing. This further leads to fibrosis as seen in this study (Figure 7). Interestingly, we also found mast cells among the infiltrated inflammatory cells. Mast cells have a major role in the pathophysiology of cardiovascular disorders [22]. Our data suggest that mast cells may promote fibrosis in the stressed and injured heart. We believe that the presence of JAK2V617F in these

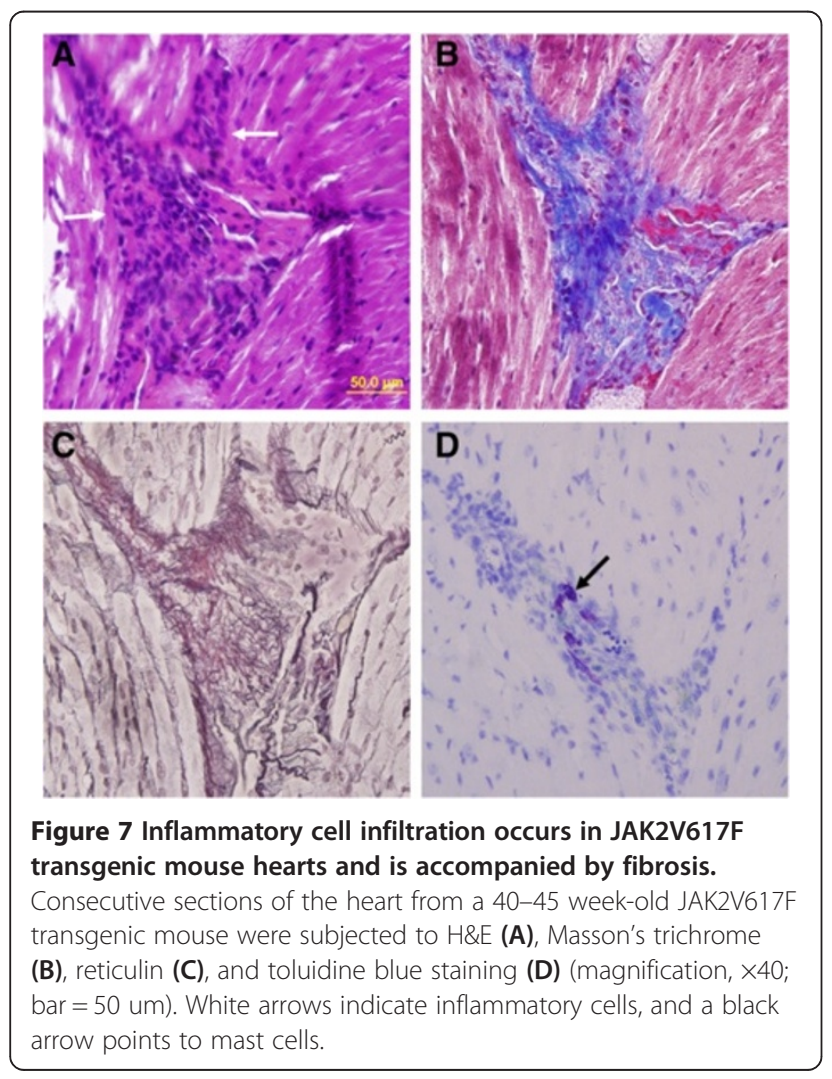

inflammatory cells further enhances their ability to infiltrate tissues thereby causing more profound damages. Identification of JAK2V617F has provided an excellent target for drug development. Many potent JAK2 inhibitors have been developed, and some have shown clinical benefits in treatment of myelofibrosis [31-34]. These inhibitors should also be useful for treating cardiovascular complications associated with MPNs.

\section{Conclusions}

We have demonstrated that JAK2V617F-induced MPNs can further lead to cardiac hypertrophy in mice. This has major implications for our understanding of complications that occur in MPN patients. Our data help to explain the high morbidity and mortality of MPN patients due to cardiovascular events. We have further demonstrated that the cardiac remodeling in JAK2V617F transgenic mice is manifest in fibrosis involving not only type I collagen but also type III reticulin fibers. By linking a hematological

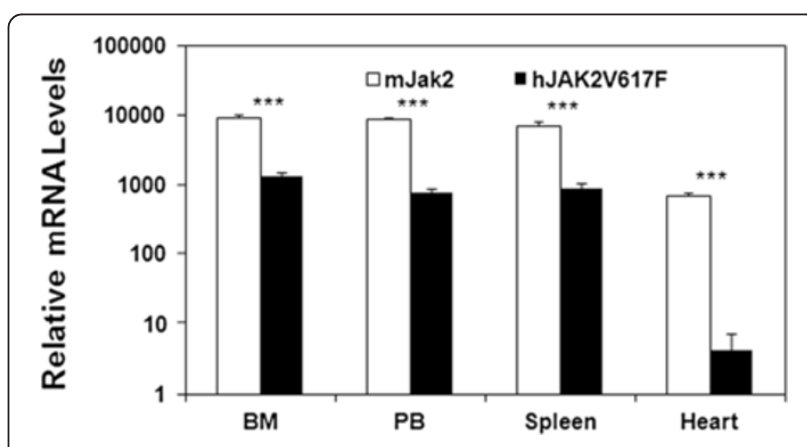

Figure 8 Real time PCR assays revealed marginal expression of transgenic JAK2V617F in the mouse heart. Expressions of the endogenous mouse Jak2 gene and the JAK2V617F transgene in the bone marrow (BM), peripheral blood (PB), spleen, and heart of 40-weekold JAK2V617F transgenic mice were determined by real time PCR. Data represent relative mRNA levels (mean $\pm S D, n=3$ ) normalized to mouse GAPDH in arbitrary units. *** $\mathrm{P}<0.001$ 
malignancy with heart diseases, JAK2V617F transgenic mice thus represent a unique model system to study cardiovascular diseases as well as blood disorders.

\section{Materials and methods Animals}

JAK2V617F transgenic mice were generated as previously described [19]. The JAK2V617F transgene is under the control of the vav-1 promoter which drives gene expression only in hematopoietic cells. These mice have been crossed with wild type C57BL/6 mice for over 10 generations. Homozygous line A JAK2V617F mice were used in this study. These mice carry 26 copies of the JAK2V617F transgene [19]. Wild type C57BL/6 were purchased from The Jackson Laboratory and used as control together with non-transgenic siblings of JAK2V617F transgenic mice. At least 10 mice with about equal male and female representations were used for each control or experimental group. Animals were housed in ventilated cages under standard conditions. This study was carried out in strict accordance with the recommendations in the Guide for the Care and Use of Laboratory Animals of the National Institutes of Health.

\section{Mouse tissue collection, fixation, and sectioning}

Mice were weighed and put under deep anesthesia through inhalation of isoflurane. Terminal blood collection was performed by removing the eyeball from the socket [35]. Hearts were then removed, blotted free of blood, and weighed. This is followed by fixation in $10 \%$ neutral buffered formalin overnight at room temperature and subsequent embedding in paraffin. Tissue sections $(5 \mu \mathrm{m})$ were cut from various positions.

\section{Histochemical staining, image acquisition, and digital quantification}

Tissue sections were deparaffinized and then subjected to H\&E, Masson's trichrome, reticulin, and toluidine blue staining by using reagents and kits from Sigma-Aldrich following standard protocols. Slides were viewed with an Olympus BX-51 upright microscope equipped with U Plan Fluorite objectives. Images were acquired using a DP71 digital camera with the DP-BSW-V3.1 camera control software (Olympus) and were processed with the Adobe Photoshop software. Quantification of histochemical stain images was done by using the NIH ImageJ program. Cardiac sections from at least 10 mice per group were analyzed. The thickness at the obtuse margin of the left ventricle of each heart was measured, excluding trabeculations. Cardiomyocyte size was assessed by measuring cross-sectional area of cardiomyocytes from H\&E-stained fields randomly selected.

\section{Total RNA isolation and real time PCR analysis}

Total RNAs were isolated from mouse tissues by using the RNeasy Mini kit (Qiagen), and single strand cDNAs were synthesized with equal amounts of total RNAs by using the QuantiTect reverse transcription kit from Qiagen. Real time PCR was performed with iQ SYBR Green Supermix (Bio-Rad) and primers specific for endogenous mouse Jak2, transgenic human JAK2V617F, and mouse glyceraldehyde-3-phosphate dehydrogenase (GAPDH) as previously described [19].

\section{Statistical analysis}

Statistical analyses were performed using the GraphPad program. Differences of samples between 2 groups were accessed using $t$ tests. $P$ values less than 0.05 (2-tailed) were considered significantly different.

\section{Abbreviations}

MPNs: Myeloproliferative neoplasms; PV: Polycythemia vera; ET: Essential thrombocythemia; PMF: Primary myelofibrosis; H\&E: Hematoxylin and eosin.

\section{Competing interests}

The authors declare no conflict of interests.

\section{Authors' contributions}

KS performed the research and wrote the manuscript; WZ, YC, and WTH performed the research; PY and ZJZ designed the research and wrote the manuscript. All authors read and approved the manuscript.

\section{Acknowledgements}

This work was supported by grant no. 81270315 from National Natural Science Foundation of China (to P Yang) and grants from the National Institutes of Health (HL094591), Oklahoma Center for the Advancement of Science \& Technology, and the MPN foundation (to ZJ Zhao).

Received: 10 February 2014 Accepted: 15 March 2014

Published: 19 March 2014

\section{References}

1. Levine RL, Gilliland DG: Myeloproliferative disorders. Blood 2008, 112:2190-2198.

2. Tefferi A: The history of myeloproliferative disorders: before and after Dameshek. Leukemia 2008, 22:3-13.

3. Campbell PJ, Green AR: The myeloproliferative disorders. N Engl J Med 2006, 355:2452-2466.

4. Kvasnicka HM, Thiele J: Prodromal myeloproliferative neoplasms: the 2008 WHO classification. Am J Hematol 2010, 85:62-69.

5. Tefferi A, Thiele J, Orazi A, Kvasnicka HM, Barbui T, Hanson CA, Barosi G, Verstovsek S, Birgegard G, Mesa R, Reilly JT, Gisslinger H, Vannucchi AM, Cervantes F, Finazzi G, Hoffman R, Gilliland DG, Bloomfield CD, Vardiman JW: Proposals and rationale for revision of the World Health Organization diagnostic criteria for polycythemia vera, essential thrombocythemia, and primary myelofibrosis: recommendations from an ad hoc international expert panel. Blood 2007, 110:1092-1097.

6. Tefferi A, Vainchenker W: Myeloproliferative neoplasms: molecular pathophysiology, essential clinical understanding, and treatment strategies. J Clin Oncol 2011, 29:573-582.

7. Finazzi G, Barbui T: How I treat patients with polycythemia vera. Blood 2007, 109:5104-5111.

8. Beer PA, Erber WN, Campbell PJ, Green AR: How I treat essential thrombocythemia. Blood 2011, 117:1472-1482.

9. Tefferi A: How I treat myelofibrosis. Blood 2011, 117:3494-3504.

10. Kim J, Haddad RY, Atallah E: Myeloproliferative neoplasms. Dis Mon 2012, 58:177-194.

11. Spivak JL: Polycythemia vera: myths, mechanisms, and management. Blood 2002, 100:4272-4290. 
12. Finazzi $G$, Barbui $T$ : Risk-adapted therapy in essential thrombocythemia and polycythemia vera. Blood Rev 2005, 19:243-252.

13. Baxter EJ, Scott LM, Campbell PJ, East C, Fourouclas N, Swanton S, Vassiliou GS, Bench AJ, Boyd EM, Curtin N, Scott MA, Erber WN, Green AR, Cancer Genome Project: Acquired mutation of the tyrosine kinase JAK2 in human myeloproliferative disorders. Lancet 2005, 365:1054-1061.

14. Levine RL, Wadleigh M, Cools J, Ebert BL, Wernig G, Huntly BJ, Boggon TJ, Wlodarska I, Clark JJ, Moore S, Adelsperger J, Koo S, Lee JC, Gabriel S, Mercher T, D'Andrea A, Fröhling S, Döhner K, Marynen P, Vandenberghe P, Mesa RA, Tefferi A, Griffin JD, Eck MJ, Sellers WR, Meyerson M, Golub TR, Lee SJ, Gilliland DG: Activating mutation in the tyrosine kinase JAK2 in polycythemia vera, essential thrombocythemia, and myeloid metaplasia with myelofibrosis. Cancer Cell 2005, 7:387-397.

15. James C, Ugo V, Le Couédic JP, Staerk J, Delhommeau F, Lacout C, Garçon L, Raslova H, Berger R, Bennaceur-Griscelli A, Villeval JL, Constantinescu SN, Casadevall N, Vainchenker W: A unique clonal JAK2 mutation leading to constitutive signalling causes polycythaemia vera. Nature 2005, 434:1144-1148.

16. Kralovics R, Passamonti F, Buser AS, Teo SS, Tiedt R, Passweg JR, Tichelli A Cazzola M, Skoda RC: A gain-of-function mutation of JAK2 in myeloproliferative disorders. N Engl J Med 2005, 352:1779-1790

17. Zhao R, Xing S, Li Z, Fu X, Li Q, Krantz SB, Zhao ZJ: Identification of an acquired JAK2 mutation in polycythemia vera. J Biol Chem 2005, 280:22788-22792.

18. Zhao W, Gao R, Lee J, Xing S, Ho WT, Fu X, Li S, Zhao ZJ: Relevance of JAK2V617F positivity to hematological diseases-survey of samples from a clinical genetics laboratory. J Hematol Oncol 2011, 4:4.

19. Xing S, Wanting TH, Zhao W, Ma J, Wang S, Xu X, Li Q, Fu X, Xu M, Zhao ZJ: Transgenic expression of JAK2V617F causes myeloproliferative disorders in mice. Blood 2008, 111:5109-5117.

20. Nicoletti A, Michel JB: Cardiac fibrosis and inflammation: interaction with hemodynamic and hormonal factors. Cardiovasc Res 1999, 41:532-543.

21. Castellar A, Remedio RN, Barbosa RA, Gomes RJ, Caetano FH: Collagen and reticular fibers in left ventricular muscle in diabetic rats: Physical exercise prevents its changes? Tissue Cell 2011, 43:24-28.

22. Kennedy S, Wu J, Wadsworth RM, Lawrence CE, Maffia P: Mast cells and vascular diseases. Pharmacol Ther 2013, 138:53-65.

23. Jin X, Zhao W, Shi K, Ho WT, Zhao ZJ: Generation of a new congenic mouse strain with enhanced chymase expression in mast cells. PLoS One 2013, 8:e84340.

24. Gattenlohner S, Ertl G, Einsele H, Kircher S, Muller-Hermelink HK, Marx A: Cardiac JAK2 mutation V617F in a patient with cardiomyopathy and myeloproliferative disease. Ann Intern Med 2008, 149:69-71.

25. Foshay K, Rodriguez G, Hoel B, Narayan J, Gallicano GI: JAK2/STAT3 directs cardiomyogenesis within murine embryonic stem cells in vitro. Stem Cells 2005, 23:530-543.

26. Ogilvy S, Elefanty AG, Visvader J, Bath ML, Harris AW, Adams JM: Transcriptional regulation of vav, a gene expressed throughout the hematopoietic compartment. Blood 1998, 91:419-430.

27. Letcher RL, Chien S, Pickering TG, Sealey JE, Laragh JH: Direct relationship between blood pressure and blood viscosity in normal and hypertensive subjects. Role of fibrinogen and concentration. Am J Med 1981, 70:1195-1202

28. Fowkes FG, Lowe GD, Rumley A, Lennie SE, Smith FB, Donnan PT: The relationship between blood viscosity and blood pressure in a random sample of the population aged 55 to 74 years. Eur Heart J 1993, 14:597-601.

29. Cinar Y, Demir G, Paç M, Cinar AB: Effect of hematocrit on blood pressure via hyperviscosity. Am J Hypertens 1999, 12:739-743.

30. Ciuffetti G, Schillaci G, Lombardini R, Pirro M, Vaudo G, Mannarino E: Prognostic impact of low-shear whole blood viscosity in hypertensive men. Eur J Clin Invest 2005, 35:93-98.

31. Verstovsek S, Kantarjian H, Mesa RA, Pardanani AD, Cortes-Franco J, Thomas DA, Estrov Z, Fridman JS, Bradley EC, Erickson-Vittanen S, Vaddi K, Levy R, Tefferi A: Safety and efficacy of INCB018424, a JAK1 and JAK2 inhibitor, in myelofibrosis. N Engl J Med 2010, 363:1117-1127.

32. Mesa RA, Cortes J: Optimizing management of ruxolitinib in patients with myelofibrosis: the need for individualized dosing. J Hematol Oncol 2013, 6:79.
33. Randhawa J, Ostojic A, Vrhovac R, Atallah E, Verstovsek S: Splenomegaly in myelofibrosis-new options for therapy and the therapeutic potential of Janus kinase 2 inhibitors. J Hematol Oncol 2012, 5:43.

34. Talpaz M, Paquette R, Afrin L, Hamburg SI, Prchal JT, Jamieson K, Terebelo HR, Ortega GL, Lyons RM, Tiu RV, Winton EF, Natrajan K, Odenike O, Claxton D, Peng W, O'Neill P, Erickson-Viitanen S, Leopold L, Sandor V, Levy RS, Kantarjian HM, Verstovsek S: Interim analysis of safety and efficacy of ruxolitinib in patients with myelofibrosis and low platelet counts. J Hematol Oncol 2013, 6:81.

35. Hoff J: Methods of blood collection in the mouse. Lab Anim 2000, 29:47-53.

doi:10.1186/1756-8722-7-25

Cite this article as: Shi et al:: Cardiac hypertrophy associated with myeloproliferative neoplasms in JAK2V617F transgenic mice. Journal of Hematology \& Oncology 2014 7:25.

\section{Submit your next manuscript to BioMed Central and take full advantage of:}

- Convenient online submission

- Thorough peer review

- No space constraints or color figure charges

- Immediate publication on acceptance

- Inclusion in PubMed, CAS, Scopus and Google Scholar

- Research which is freely available for redistribution 